ORIGINAL RESEARCH

\title{
Leadership Succession Preparedness and Sense of Urgency in Canadian Hospital Pharmacy
}

\author{
Zack Dumont, Neil J MacKinnon, William Mueller, Kelly Babcock, and Jenelle Sobotka
}

\begin{abstract}
Background: Leadership turnover is unavoidable in all organizations, including hospital pharmacy departments. Succession planning can promote organizational stability, among other benefits.

Objectives: To gather a contemporary, nationwide measure of the level of preparedness for department leadership succession and to gain related insight from a variety of pharmacy leaders.

Methods: This study was an environmental scan of Canadian hospital pharmacy leaders. An online survey was conducted to identify the current rate of succession planning; to describe existing succession plans; to determine the perceived need for succession planning; and to describe strategies for, barriers to, and facilitators of succession planning.

Results: Eighty-three responses were received. Thirteen respondents (16\%) reported that their hospital pharmacy departments had a succession plan, and 13 (16\%) of individuals had known successors. Most respondents $(64 / 75$ [85\%]) perceived succession plans to be rare or nonexistent across Canada. However, 72\% (54/75) felt that succession planning was needed for their own leadership position. The most common barriers to succession planning were a lack of formal structure or tools, lack of plan implementation, unionization, and lack of career ladder positions. Select facilitators to succession planning identified by respondents were having a strong existing leadership and having an abundant pool of capable successors.

Conclusions: Most Canadian hospital pharmacy departments and individual leaders represented in this survey were not prepared with succession plans. A collective effort to proactively enact succession planning in Canadian hospital pharmacy departments would have multiple benefits for existing and aspiring leaders and, ultimately, the profession as a whole.
\end{abstract}

Keywords: leadership, management, succession, human resources, competency

Can J Hosp Pharm. 2019;72(2):119-25

\section{RÉSUMÉ}

Contexte : Tout organisme, y compris les services de pharmacie d'hôpitaux, fait face au renouvellement inévitable de sa direction. La planification de la relève peut, entre autres avantages, favoriser la stabilité organisationnelle.

Objectifs : Brosser un portrait national et actuel de la capacité des services de pharmacie de faire face au renouvellement de leur direction et obtenir le point de vue de différents leaders en pharmacie sur le sujet.

Méthodes : La présente étude est une analyse du contexte des leaders en pharmacie hospitalière du Canada. Un sondage en ligne a permis de déterminer le degré actuel de planification de la relève, de décrire les plans de relève mis en place, de déterminer dans quelle mesure une planification de la relève est nécessaire et de décrire les stratégies à adopter pour mener une planification de la relève ainsi que les éléments y faisant obstacle ou la facilitant.

Résultats : Les investigateurs ont reçu 83 réponses. Treize répondants (16\%) ont indiqué que les services de pharmacie de leur hôpital possédaient un plan de relève et tous les $13(16 \%)$ connaissaient les successeurs. La plupart des répondants $(64 / 75$ [85 \%]) croyaient que les plans de relève étaient rares, voire inexistants, au Canada. Cependant, $72 \%$ (54/75) estimaient que leur poste de direction nécessitait une planification de la relève. Les obstacles à la planification de la relève le plus souvent évoqués étaient : l'absence de structure ou d'outils formels, l'absence de mise en ouvre d'un plan, la syndicalisation et le manque de postes offrant des possibilités d'avancement. Parmi les éléments facilitant la planification de la relève, les répondants ont mentionné : la présence d'un leadership fort et l'accès à un important bassin de candidats compétents.

Conclusions : La plupart des services de pharmacie d'hôpitaux canadiens et des dirigeants représentés dans le sondage n'étaient pas en mesure de s'appuyer sur un plan de relève. Un travail collectif de mise en œuvre proactive d'une planification de la relève dans les services de pharmacie d'hôpitaux canadiens aurait de multiples avantages pour les dirigeants en place et ceux appelés à le devenir et, ultimement, pour la profession dans son ensemble.

Mots clés : leadership, direction, succession, ressources humaines, compétence 


\section{INTRODUCTION}

$\mathrm{T}$ he CSHP position statements on pharmacy practice in hospitals and other collaborative health care settings guide pharmacy departments to encourage lifelong learning in the provision of direct patient care, the refinement of personal practice skills, and the development of leadership skills. ${ }^{1}$ Leadership development is carried out in many ways, including teaching, preceptorship, coaching, and mentoring. In question, however, is the degree of emphasis placed on truly "passing the torch" from one hospital pharmacist to another, through a formal succession plan. Because turnover in leadership can be unpredictable and no less unavoidable, ${ }^{2}$ broadly applicable advantages can be realized by having a succession plan, which has been described as "a deliberate process designed to promote organizational stability during changes in leadership". ${ }^{3}$

Maintaining effective organizational performance, retaining knowledge assets, ${ }^{3}$ and making transitions easier for the incoming leaders are only a few of the benefits of succession planning. In a retrospective analysis (not specific to pharmacy) published in 2011, Bidwell found that internally hired recruits performed better and were less likely to exhibit turnover than external recruits. ${ }^{4}$ Yet other research suggests that many businesses and corporations are not prepared with a succession plan for the CEO position, ${ }^{5,6}$ let alone other positions. As noted by the American Society of Health-System Pharmacists' Statement on Leadership as a Professional Obligation, "Leadership is a professional obligation of all pharmacists and not the exclusive responsibility of pharmacists who hold formal leadership roles or titles."7 Given that leadership sets the culture and expectations for the rest of the organization, it may be surmised that key positions, from "the top" to the front line, are all vulnerable to the same lack of succession preparedness.

The pharmacy profession is not protected from these potential deficiencies. In a prospective study published in 2013, White and Enright found that of the approximately $75 \%$ of managers or directors in US hospital pharmacies who planned to leave their positions within 10 years, fewer than half had a succession plan. ${ }^{8}$ Furthermore, only $17 \%$ of these leaders felt they had someone who could fill vacant leadership positions within 2 months. In Canada, a 2007 leadership survey conducted by Musing and others ${ }^{9}$ determined that only 24 (17.9\%) of 134 respondents had a succession plan in place or in development. Shortly thereafter, a 2008 report by the Canadian Society of Hospital Pharmacists (CSHP) Hospital Pharmacy Management Task Force stated that "changing management roles, the appointment of nonpharmacist managers, and ongoing vacancies in formal leadership positions" corroborated the lack of preparation for succession planning, and pinpointed a looming leadership gap. ${ }^{10}$ The report went on to explain that $20 \%$ to $40 \%$ of pharmacists holding manager-type positions at that time were projected to retire within 10 to
15 years. ${ }^{10}$ With an aging workforce, ${ }^{11}$ generational changes, ${ }^{10}$ shifting public and stakeholder demands, increasing requirements for accountability and transparency, and a long-standing lack of formal leadership training or emphasis, ${ }^{10}$ developing a succession plan had never been more important.

Performed about 10 years after the survey by Musing and others ${ }^{9}$ and the report of the CSHP Task Force, ${ }^{10}$ the purpose of this 2018 study was to gather a contemporary nationwide measure of the level of preparedness for pharmacy department leadership succession and to gain related insight from a variety of pharmacy leaders. The specific objectives were to identify the current rate of succession planning; to describe existing succession plans; to determine the perceived need for succession planning; and to describe strategies for, barriers to, and facilitators of succession planning.

\section{METHODS}

This study was a prospective environmental scan of Canadian hospital pharmacy leaders. There were 2 main components: telephone interviews followed by a survey. A preliminary set of telephone interview and survey questions was adapted by the research team (Z.D., N.J.M., W.M., and K.B.) from an earlier study. ${ }^{12}$ The principal investigator (Z.D.) conducted telephone interviews with diverse leaders such as CSHP board members, pharmacy association leaders, directors of pharmacy, and new practitioners. The aim was to seek opinions and to help refine the survey, which was then carried out online, as described below. The study was approved by the University of Cincinnati Institutional Review Board.

\section{Telephone Interviews}

The interview participants, who were identified through nonprobabilistic purposive sampling, ${ }^{13}$ were targeted to encompass a diverse spectrum of demographic characteristics, backgrounds, and experience. Potential participants were contacted by e-mail and asked to sign a consent form. At the beginning of their interview, participants were presented with a synopsis of the research project, the purpose of the interview, and their roles and responsibilities as participants in the interview component of the study. The discussion covered the existence or absence of succession plans and factors used for identifying candidates, and participants were asked to consider the draft survey questions and to propose new questions. The interview questions are available in Appendix 1 (https://www.cjhp-online.ca/index.php/cjhp/issue/ view/189/show Toc). The sessions were audiorecorded and transcribed, and the transcripts were provided to participants upon request.

After the telephone interviews, the research team reviewed the findings to identify themes and incorporated participants' suggestions and comments into the survey. 
This single copy is for your personal, non-commercial use only.

For permission to reprint multiple copies or to order presentation-ready copies for distribution, contact CJHP at publications@cshp.ca

\section{Survey}

The survey instrument was pilot tested by 3 pharmacists in leadership positions in hospital pharmacy who were not otherwise involved in this study. The testers were directed to provide feedback specifically related to survey logic, terminology, and instructions requiring clarification. The survey invitation and questions were revised before launch on the basis of feedback provided. The final survey, comprising 22 questions, was conducted with the online survey tool REDCap (https://www.project-redcap.org). One question was an ice-breaker regarding leadership, 15 of the questions were related specifically to succession planning, 5 questions were used to collect demographic characteristics such as location, facility type, and hospital size, and the last question was a call to action to forward the survey to other potential participants. The survey questions related to leadership and succession planning are available in Appendix 2 (https://www.cjhp-online.ca/index.php/cjhp/issue/ view/189/showToc).

Once the survey was under way, participant recruitment was by nonprobabilistic, convenience, multiframe, and network sampling of Canadian hospital pharmacist leaders, ${ }^{13}$ specifically those who held a leadership position or considered their role to be key to the organization. This definition of leadership was used to ensure inclusion of both formal and informal leaders, independent of official titles or designations.

Participants were given 2 weeks to complete the survey (March 12 to March 26, 2018). Completion of the survey was interpreted as provision of consent to participate. In preparation for launch of the survey, an e-mail invitation, which included a link to the online survey, was sent by the principal investigator (Z.D.) to the administrator of the CSHP Pharmacy Specialty Networks (PSNs) and the CSHP's publications administrator. ${ }^{14}$ The PSNs are web-, app-, and e-mail-based communication networks for CSHP members. The CSHP employee responsible for PSN administration distributed the invitation to the members of 2 PSNs: Clinical Practice Leaders and Hospital Pharmacy Management. ${ }^{15}$ On days 5 and 12 , the publications administrator distributed the survey invitation in the regularly scheduled weekly CSHP newsletter (the eBulletin), which is sent to all members and supporters. ${ }^{16}$ Reminder PSN and newsletter notifications were sent by CSHP staff at the midway mark (i.e., 1 week after the survey opened and before the survey closed). Also at the midpoint, the newsletter and survey link were forwarded by the principal investigator to the president of each of the 9 provincial CSHP branches and the equivalent representative from the affiliate Association des pharmaciens des établissements de santé du Québec, requesting that the survey invitation be shared with pharmacy directors, managers, and branch council members.

\section{Data Analysis}

Data from the survey are descriptive and were evaluated using Microsoft Excel. When the response option of "other" was selected, the response was categorized as "other", and free-text comments were aggregated.

\section{RESULTS}

\section{Telephone Interviews}

Interviews were completed (mean duration $32 \mathrm{~min}$ ) with 8 participants from the CSHP board and branch councils: $2 \mathrm{CSHP}$ staff members, 3 executive officers, 2 branch presidents, and 1 branch delegate. Of the 8 participants, 6 were women and 2 were men. One participant had less than 10 years of pharmacy experience, and the others had 10 years or more. Themes extracted from the telephone interviews are listed in Box 1. Barriers identified by interview participants were incorporated into the survey.

\section{Survey Distribution and Respondents}

The survey invitation was sent to the 168 members of the Clinical Practice Leaders PSN and the 130 members of the Hospital Pharmacy Management PSN. ${ }^{17}$ The e-mail messages containing the eBulletin newsletter were received by 2983 members and supporters, of whom 1086 opened the first e-mail and 28 clicked on the link to the survey invitation; the second newsletter was opened by 1027 recipients and the survey link clicked 12 times (O. Chrzanowska, Web Administrator, CSHP, personal communication by e-mail, March 27, 2018). An additional 115 pharmacists were reported to have received the invitation through forwarding by initial survey respondents.

A total of 83 survey responses were received. Given the potential overlap between the PSNs, as well as overlap with newsletter and forwarding recipients, a denominator could not be determined and a response rate was therefore not calculated. The demographic characteristics of survey respondents are presented in Table 1.

\section{Box 1. Succession Planning Themes Identified in Telephone Interviews ( $\boldsymbol{n}=\mathbf{8}$ Respondents)}

Clinical skill and experience of ideal successors was emphasized; commercial or business acumen was de-emphasized

Hospital pharmacy leadership requires some unique attributes: systems-thinking, ability to manage outside of the profession or areas of expertise (e.g., pharmacist as manager of technicians; clinicians as managers of distribution staff), ability to navigate rapid change (e.g., changing scopes of practice, therapeutic developments)

Leadership competencies (of candidates) are most critical in selecting a successor

Leadership experience of the successor is important (in selection process), but not critical; many pharmacists have suitable experience Positions conducive to succession planning are not confined to the top positions, such as the department head

Succession planning is of high importance

Succession planning is the responsibility of the current pharmacy leaders; human resources' role is to support and provide framework 


\section{Table 1. Demographic Characteristics of Survey Respondents}

\begin{tabular}{lcc} 
Characteristic & \multicolumn{2}{c}{ No. (\%) of } \\
Respondents*
\end{tabular}

\section{Succession Planning}

Of the 83 respondents, $13(16 \%)$ reported that their organizations had a succession planning program in place, 52 (63\%) reported no program, 17 (20\%) did not know whether a program existed, and 1 person did not answer the question. With respect to the perceived prevalence of succession plans in hospital pharmacy departments across Canada $(n=75$ respondents), 64 respondents (85\%) were of the opinion that such programs were somewhat rare to never in place, $5(7 \%)$ had a neutral opinion, $6(8 \%)$ thought such programs were somewhat common, and none responded that programs were common or always in place.

Eight respondents (11\%) stated that they were currently an identified successor for another position $(n=75), 45(60 \%)$ were not identified as a successor, and $22(29 \%)$ did not know their status in this regard. When asked whether they had identified a successor for their current position $(n=75), 12(16 \%)$ responded "yes" and 63 (84\%) responded "no". Four respondents reported that they had arrived at their current position via a succession plan $(n=74)$, another 66 (89\%) reported not being in their current position as a result of a succession plan, and 4 did not know.

Of the 13 respondents who reported that succession planning programs were in place within their respective organizations, the programs were regarded as mandatory in 3 cases; otherwise, 5 reported voluntary programs, 3 did not know whether their program was mandatory, and the remainder did not respond to the question. In all 13 cases (100\%), oversight of the existing program was internal to the pharmacy department.

The level of agreement and disagreement with statements about the need for a succession plan for specified positions, such as staff pharmacist and manager, was variable (see Figure 1). When asked whether a successor was needed for the respondent's current position $(n=75), 54(72 \%)$ responded "yes", $6(8 \%)$ did not think it was necessary, and $15(20 \%)$ did not know.

${ }^{\star}$ Except where indicated otherwise.

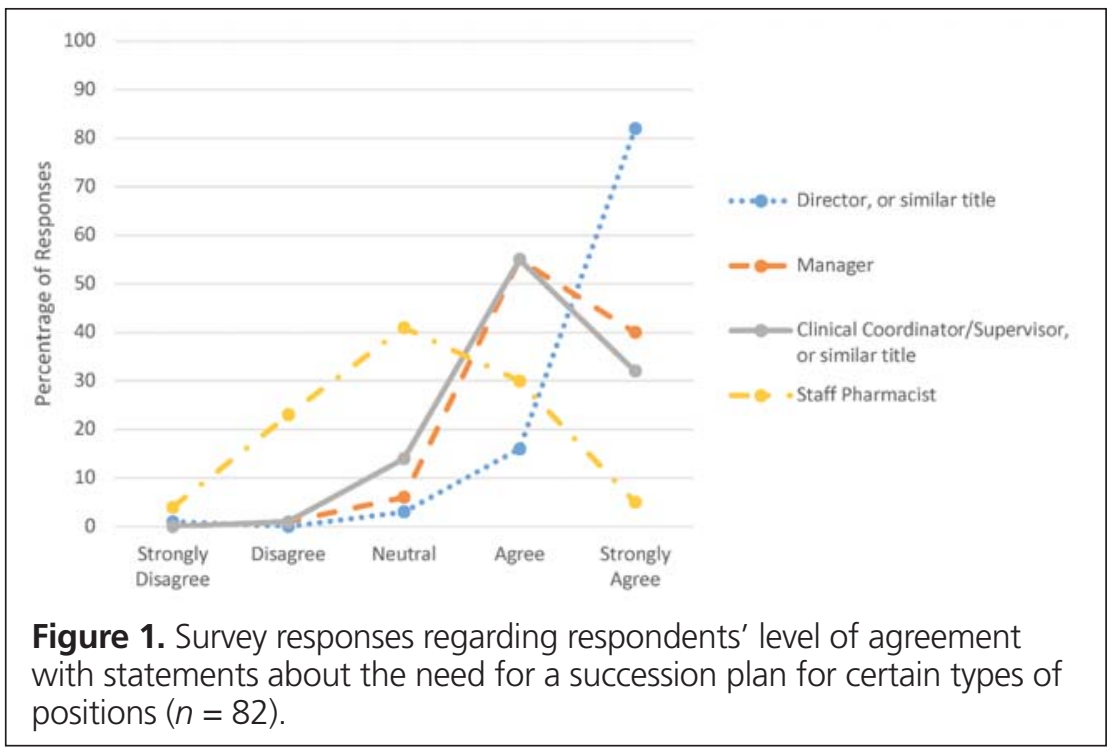




\section{Table 2. Barriers to Succession Planning in Hospital Pharmacy ( $n=83$ Respondents)}

Barrier

Lack of formal planning structure/tools

Unionized environment, whereby seniority is

often prioritized over performance

Lack of succession plan implementation

Lack of career ladder positions

Uncertainty of future organizational structure

Lack of opportunities to assess or develop

competencies (i.e., leadership competencies)

in pool of potential successors

Cursory approach to formal succession plans

Concerns that a developing successor will leave

Factors external to the workplace

(e.g., family/parental leave)

Othert

* Respondents were asked to select all that applied.

tExamples of responses: "potential candidates are not interested

in leadership and would prefer staying in their current roles",

"lack of resources to develop and/or maintain leadership

competencies", "lack of time to implement a succession plan".

Regarding oversight of a succession planning program, the majority (69 respondents) felt that the pharmacy department should have primary responsibility, with the human resources department supporting the process.

When asked to assess the value of leadership experience (among potential successors) on a scale from 1 to 6 , where $1=$ not required and $6=$ required $(n=82), 41$ respondents $(50 \%)$ gave a score of 5 or 6,39 respondents (48\%) gave a score of 3 or 4 , and 2 respondents (2\%) gave a score of 1 or 2 .

When asked to rank the level of importance of the following factors that may be used in selecting a successor, collated responses were (in order from most to least important) leadership competency, attitude, existing/potential friendship, work ethic, political connection, and clinical competence.

Participants were asked to identify the main barriers to succession planning by selecting from the list developed through telephone interviews. Lack of formal structure or tools for planning was the most frequently identified response (Table 2).

Participants were also asked, by means of an open-ended question, to identify facilitators or enablers of succession planning. Fifty-one respondents provided input on this question, and the aggregated results are presented in Box 2.

\section{DISCUSSION}

This study sought to gather data for a contemporary measure of the level of preparedness for leadership succession in Canadian hospital pharmacy departments and to gain related insight from current leaders. The responses showed a scarcity of succession plans, with only $16 \%$ of departments having a succession planning program, only $16 \%$ of individuals having known successors, and most (85\%) reporting their perception that succession plans are rare or nonexistent across Canada. Further-

\section{Box 2. Facilitators of Succession Planning in Hospital Pharmacy ( $n=51$ Respondents)*}

Availability of candidates with desire to lead

Collective sense of urgency (e.g., early identification of impending retirements) and acceptance of the issue at hand

Competent existing leadership (e.g., willing to share responsibilities, vision)

Flexibility in existing roles (to accommodate leadership development opportunities)

Formal and mandatory succession plans

Leadership competency assessment (e.g., recognition that leading

projects is not equivalent to leading people)

Mentorship, coaching, in-house and external leadership training and development (e.g., residency programs, PharmD rotations)

More entry-level, career ladder positions; more mixed positions with leadership and clinical responsibilities

Opportunities for staff to demonstrate leadership skills

(e.g., committee involvement)

Residency and internship programs for hospital practice

Techniques for identifying potential candidates

Top-down (including external to pharmacy) direction and support to implement plans

*Respondents provided answers in free text (no prespecified list).

more, most respondents felt that succession planning is needed, notably demonstrated by $72 \%$ stating that their position needed a successor, and most reporting that formal and informal leadership positions were in need of successors. To our knowledge, this is the first time that discordance between the level of preparedness and the perceived need and responsibility for succession planning has been explicitly characterized. Responses broadly conveyed the perception that succession planning for the pharmacy department is the pharmacy profession's responsibility; human resources departments should not lead, but rather should assist and provide support. The most common barriers to succession planning were a lack of formal structure or tools, lack of plan implementation, unionization, and lack of career ladder positions. Facilitators to succession planning were reported as strong existing leadership skills (e.g., good delegation, vision) and an abundant pool of capable successors.

The lack of preparedness for leadership succession has been a known issue in Canadian hospital pharmacy for more than a decade. The 2007 leadership survey found that only $18 \%$ of hospital pharmacies had a succession plan. ${ }^{9}$ The subsequent CSHP Task Force report, published in 2008, recommended establishment of formal succession plans,${ }^{10}$ but the results of the current survey study suggest that this recommendation has not been heeded in the years since.

The results of the current study also suggest that Canadian hospital pharmacy leaders today believe that the gap in succession planning needs to be addressed; this study may thus serve as a critical starting point in this effort.

Once succession planning programs are in place, a number of positive effects can be realized. Consciously or unconsciously 
aspiring leaders may be motivated to become identified as successors, departments and individuals could conduct regular leadership assessments and inventories, ${ }^{18}$ and current leaders could "share their load" with leadership aspirants, which would be mutually beneficial to themselves and to the development of their successors.

The limitations of this study are worth noting. First, a French version was not developed and responses were therefore limited to English-speaking participants. Respondents were not asked to confirm that they were indeed Canadian hospital pharmacists, and no strategies were used to prevent multiple responses from the same person. Moreover, the subjective nature of responses, during both the telephone interviews and the survey, may have limited the representativeness. The risk of selection bias cannot be ruled out. Because CSHP members were the only "targets" for direct invitation, responses may have come from those most interested in hospital pharmacy and the preservation of its leadership. Lastly, specific emphasis on sample size and power was not required, because no comparisons were done and the results are reported descriptively. However, this limited our ability to test for saturation of themes. Given the inability to calculate the number of people who received the invitation, it is challenging to determine whether the number of responses was expected and capable of characterizing hospital pharmacy leaders. What is known is that $4.5 \%$ of hospital pharmacists and technicians who responded to the 2013/14 Hospital Pharmacy in Canada Survey self-identified as managers. ${ }^{19}$ In the context of the approximately 2800 CSHP members at the time of the survey, this proportion would by represented by about 126 potential respondents, and the 83 responses to the survey would equate to a response rate of about 64\%. However, a denominator of 126 should be used with caution: it may be an overestimation, given that technician managers were included in the $4.5 \%$ value noted above, or it may be an underestimation, given that the survey invitation was extended to anyone who considered their role key to the organization, without necessarily holding a formal leadership title such as "manager". The response rate may be further validated by another CSHP member survey that was completed only a few weeks prior to ours, which was open to all CSHP members and which received 116 responses (C. Lyder, Director of Members and Programs, CSHP, verbal communication, April 5, 2018).

Countering the impact of these limitations were certain elements of the study design; in particular, the survey was based on previously tested questions ${ }^{12}$ and was tested in both the interview and pilot phases. In addition, the survey design included a mix of closed-ended and open-ended questions, with space available for free-text comments or expansion of more restricted responses.

The lack of succession planning identified in this study must be addressed with a sense of urgency by individual pharmacists, current leaders, and the profession at large. We therefore recommend a collectively focused effort centred on succession planning. Our approach to recommendations differs from the 2008 Task
Force Report, ${ }^{10}$ which contained a substantial number of high-level recommendations $(n=23)$, only a few of which have subsequently been enacted or tracked. Given the barriers and facilitators shared by respondents to the current survey, a worthy endeavour would be development of a national pharmacists' toolkit for succession planning. This toolkit could include fundamental information on how to start succession planning for an individual position. It could also include strategies to overcome barriers, such as gaining control over union-imposed limitations and developing leaders in a context of limited resources. Furthermore, a collective commitment to mandate succession plans within pharmacy departments would ensure that the profession is being proactive, rather than reactive to external forces. Lastly, it is recommended that the level of preparedness for leadership succession be measured regularly, perhaps through the "Human Resources" section of the Hospital Pharmacy in Canada Survey.

\section{CONCLUSION}

Most departments and individual leaders represented in this study were not prepared with succession plans, yet most felt that such planning is needed. Furthermore, the general opinion of respondents was that existing pharmacy leadership is responsible for addressing the discordance. A collective effort to proactively enact succession planning programs in Canadian hospital pharmacy departments would offer multiple benefits to existing and aspiring leaders and, ultimately, the profession as a whole.

\section{References}

1. Pharmacy practice in hospitals and other collaborative healthcare settings: position statements. Ottawa (ON): Canadian Society of Hospital Pharmacists; 2016 [cited 2017 Sep 1]. Available from: https://www.cshp.ca/positionstatements

2. Farthing K. Succession planning: the right people in the right positions at the right time. Hosp Pharm. 2013;48(3):175-6.

3. Thorndyke L, Grigsby RK. The need for succession planning. Acad Physician Sci. New York (NY): Lippincott Williams and Wilkins; 2005 Apr [cited 2017 Sep 1]. Available from: https://www.aamc.org/download/164786/data/ thorndyke_grigsby_need_for_succession_planning.pdf

4. Bidwell M. Paying more to get less: the effects of external hiring versus internal mobility. Admin Sci Q. 2011;56(3):369-407.

5. 2014 hospital CEO survey on succession planning. Healthc Exec. 2014; 29(4):74.

6. Harrell E. Succession planning: what the research says. Harvard Bus Rev. 2016 Dec [cited 2017 Sep 1]. Available from: https://hbr.org/2016/12/ succession-planning-what-the-research-says

7. American Society of Health-System Pharmacists. ASHP statement on leadership as a professional obligation. Am J Health Syst Pharm. 2011;68(23): 2293-5.

8. White SJ, Enright SM. Is there still a pharmacy leadership crisis? A sevenyear follow-up assessment. Am J Health Syst Pharm. 2013;70(5):443-7.

9. Musing E, Wong M, Jackson L, Lee J, Slote C. A focus on leadership: CSHP's 2007 national leadership survey. Can J Hosp Pharm. 2008;61(1):70-5.

10. CSHP Hospital Pharmacy Management Task Force. Planning for hospital pharmacy management, now and in the future. Can J Hosp Pharm. 2008;61 (5):374-84.

11. Ellinger LK, Trapskin PJ, Black R, Kotis D, Alexandre E. Leadership and effective succession planning in health-system pharmacy departments. Hosp Pharm. 2014;49(4):369-75.

12. Collins SK. Succession planning: perspectives of chief executive officers in US hospitals. Health Care Manag. 2009;28(3):258-63. 
This single copy is for your personal, non-commercial use only.

For permission to reprint multiple copies or to order presentation-ready copies for distribution, contact CJHP at publications@cshp.ca

13. Dillman DA, Smyth JD, Christian LM. Internet, mail, and mixed-mode surveys: the tailored design method. 3rd ed. Hoboken (NJ): John Wiley \& Sons; 2009.

14. About us - who we are. Ottawa $(\mathrm{ON})$ : Canadian Society of Hospital Pharmacists; [cited 2017 Sep 4]. Available from: https://www.cshp.ca/ who-we-are

15. Conducting surveys and research via a PSN. Ottawa (ON): Canadian Society of Hospital Pharmacists; [cited 2017 Sep 4]. Available from: https://www.cshp.ca/conducting-surveys-and-research-psn

16. eBulletin [serial publication]. Ottawa (ON): Canadian Society of Hospital Pharmacists; [cited 2017 Sep 4]. Available from: https://www.cshp.ca/ cshp-ebulletin

17. QID.io, a clinical social network for pharmacists and pharmacy professionals. Halifax (NS): QID.io [cited 2018 Mar 12]. Available from: www.qid.io

18. Axworthy S, MacKinnon N. Perceived importance and self-assessment of the skills of Canada's health-system pharmacy managers. Am J Health Syst Pharm. 2002;59(11):1090-7.

19. Hospital pharmacy in Canada 2013/2014 report. Hospital Pharmacy in Canada Editorial Board; 2015 [cited 2018 Mar 28]. Available from: http://stage.lillyhospitalsurvey.ca/hpc2/content/2015_report/ FULL-2015.pd
Zack Dumont, BSP, ACPR, MS(Pharm), is with Pharmacy Services, Saskatchewan Health Authority, Regina, Saskatchewan.

Neil J MacKinnon, BSc(Pharm), MS(Pharm), PhD, is with the James L Winkle College of Pharmacy, University of Cincinnati, Cincinnati, Ohio.

William Mueller, BSPharm, MBA, is a retired health care executive in Cincinnati, Ohio.

Kelly Babcock, BSP, ACPR, FSHP, is with Pharmacy Services, Saskatchewan Health Authority, Regina, Saskatchewan.

Jenelle Sobotka, PharmD, FAPhA, FNAP, is with the James L Winkle College of Pharmacy, University of Cincinnati, Cincinnati, Ohio.

Competing interests: None declared.

Address correspondence to:

Zack Dumont

Pharmacy Services

Saskatchewan Health Authority Regina Area

1440 14th Avenue

Regina SK S4P OW5

e-mail: zack.dumont@saskhealthauthority.ca

Funding: None received.

Acknowledgement: The authors thank Jennifer Bolt, Cathy Lyder, and Barry Lyons for pilot-testing the survey. 